\title{
Growth of diamond thin films by chemical vapour deposition
}

\author{
A K KULKARNI \\ Department of Electrical Engineering, Michigan Technological University, Houghton, MI \\ 49931, USA
}

\begin{abstract}
Deposition of diamond thin films on non-diamond substrates at low pressures ( $<760$ torr) and low temperatures $\left(<2000^{\circ} \mathrm{C}\right)$ by chemical vapour deposition (CVD) has been the subject of intense research in the last few years. The structural and the electrical properties of CVD diamond films grown on p-type $<111>$ and high-resistivity $(>100 \mathrm{k} \Omega-\mathrm{cm})$ $<100\rangle$ oriented silicon substrates by hot filament chemical vapour deposition technique are described in this review paper.
\end{abstract}

Keywords. Diamond; thin films; chemical vapour deposition; Raman spectroscopy; sheet resistivity.

\section{Introduction}

Exceptional properties of diamond have attracted the attention of the research community throughout the world to exploit these properties for a variety of applications ranging from hard coatings for drill bits to high-temperature electronics. The ability to grow thin films of diamond using inexpensive chemical vapour deposition (CVD) techniques has led to intense research on the characterization of these films in the last few years (Angus and Hayman 1988; Yarbrough and Messier 1990; Davis 1993). Several methods for diamond deposition on non-diamond substrates with high deposition rates $(10-300 \mu \mathrm{m} / \mathrm{h}$ ) have been described (Matsumoto et al 1982). The crystals grown from these processes were many micrometres in size and were often twinned and without preferred orientation relative to the substrate. Process variables such as methane concentration, substrate temperature, system pressure and flow rates of methane and hydrogen are varied to control the quality, composition, grain size, surface texture and growth rate of the films (Mercier et al 1991; Zhu et al 1991). The use of atomic hydrogen for removing co-deposited graphite (stable phase of carbon at room temperature and pressure) to result in metastable growth of diamond has been well established. The nucleation of diamond particles on non-diamond substrates has been studied extensively (Kobashi et al 1989; Meilunas et al 1989). However, no clear understanding of the nucleation process has emerged.

\section{Fabrication}

\subsection{Different kinds of CVD methods}

During the past decade, different CVD methods have been employed to grow highquality diamond thin films on a variety of substrates. The common features of all these methods are: (1) high energy densities to produce hydrocarbon species in the gas phase, (2) high substrate temperatures $\left(600-1000^{\circ} \mathrm{C}\right)$ to ensure diffusion of the species on the substrate surface to enhance nucleation, and (3) efficient utilization of 
atomic hydrogen to result in the etching of graphite. The fundamental difference in these methods is the way the chemical precursors are activated by different types of energies. The major CVD techniques are: (i) hot filament CVD and (ii) microwave plasma enhanced CVD, (iii) r.f. plasma enhanced CVD (Davis 1993). Microwave plasma enhanced CVD appears to be the most common growth technique. This method uses $2.45 \mathrm{GHz}$ microwave power as the source to dissociate the reactant gases. Highly oriented diamond films have been fabricated by this method (Stoner et al 1992). The hot filament CVD technique used in our work is described in detail below.

\subsection{Hot filament CVD system}

This is the most simple and economical diamond growth technique. As shown in figure 1 a tungsten filament is heated to about $2000^{\circ} \mathrm{C}$ to dissociate the hydrocarbonhydrogen gas mixture during the growth process. As seen in figure 1 , the reactant gases, i.e. $\mathrm{H}_{2}$ and $\mathrm{CH}_{4}$, are introduced from the top into the reaction chamber. The amount of the reactant gases is controlled by a Dyna Mass flow control system. The silicon substrates are placed on a molybdenum substrate holder and are held by molybdenum fingers. The substrates are heated by a tungsten coil placed underneath the substrate holder to independently control the substrate temperature. A type $\mathrm{K}$ thermocouple $(\mathrm{Ni}-\mathrm{Cr} / \mathrm{Ni}-\mathrm{Al})$ that is placed firmly in contact with the bottom of the substrate holder measures the substrate temperature. The temperature of the tungsten filament maintained close to $2000^{\circ} \mathrm{C}$ is sensed by an Omega two-colour (model OS 3722) optical pyrometer which can measure temperatures from 900 to $3000^{\circ} \mathrm{C}$ with an accuracy of $\pm 1 \%$.

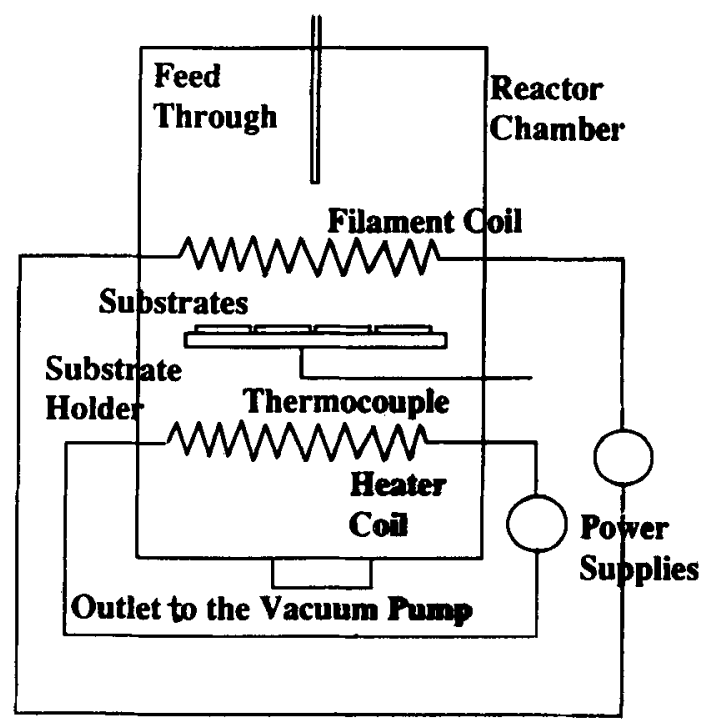

Figure 1. Schematic of the hot filament CVD system. 
Table 1. Growth paramleters.

\begin{tabular}{lccccccc}
\hline $\begin{array}{l}\text { Sample } \\
\text { no. }\end{array}$ & $\begin{array}{c}\text { Run } \\
\text { no. }\end{array}$ & $\begin{array}{c}\text { Pressure } \\
\text { (torr) }\end{array}$ & $\begin{array}{c}\mathrm{CH}_{4} / \mathrm{H}_{2} \\
\text { ratio }\end{array}$ & $\begin{array}{c}\text { Flow rate } \\
(\mathrm{Sccm})\end{array}$ & $\begin{array}{c}\text { Sub. temp. } \\
\left({ }^{\circ} \mathrm{C}\right)\end{array}$ & $\begin{array}{c}\text { Growth } \\
\text { time } \\
(\mathrm{h})\end{array}$ & $\begin{array}{c}\text { Substrate } \\
\text { type }\end{array}$ \\
\hline B1 & 21029 & 50 & $0.5 \%$ & 200 & 900 & 8 & $\mathrm{p}-(111)$ \\
B2 & 21210 & 50 & $0.75 \%$ & 200 & 875 & 8 & $\mathrm{p}-(111)$ \\
B3 & 21222 & 50 & $1.0 \%$ & 200 & 875 & 8 & $\mathrm{p}-(111)$ \\
B4 & 30318 & 50 & $1.0 \%$ & 200 & 875 & 17 & $\mathrm{p}-(100)$ \\
B5 & 30121 & 50 & $1.5 \%$ & 200 & 875 & 8 & $\mathrm{p}-(111)$ \\
B6 & 30204 & 50 & $2 \cdot 0 \%$ & 200 & 875 & 8 & $\mathrm{p}-(111)$ \\
B7 & 30513 & 40 & $0 \cdot 5 \%$ & 200 & 810 & 8 & $\mathrm{p}-(100)$ \\
B8 & 30423 & 40 & $1.0 \%$ & 200 & 875 & 8 & $\mathrm{p}-(100)$ \\
B9 & 30429 & 40 & $1.0 \%$ & 200 & 810 & 8 & $\mathrm{p}-(100)$ \\
B10 & 30504 & 40 & $1.5 \%$ & 200 & 810 & 8 & $\mathrm{p}-(100)$ \\
\hline
\end{tabular}

\subsection{Substrate preparation}

The p-type $<111>$ oriented and high-resistivity $(>100 \mathrm{k} \Omega-\mathrm{cm})<100>$ oriented silicon substrates were cleaned in acetone, etched using HF in the ultrasonic bath, and then scratched with the diamond paste ( 1 or $9 \mu \mathrm{m}$ particle size) and sonicated in the ultrasonic bath. The substrates were dried and placed in the chamber.

\subsection{Growth conditions}

Table 1 gives the details of the growth conditions on 10 different samples selected for further analysis. As seen in this table, the methane to hydrogen ratio was varied from 0.5 to $2.0 \%$ in steps to determine the optimum ratio to yield the best structural properties. The other growth parameters such as substrate temperature, pressure during growth, growth time and flow rates were maintained constant as far as possible. Details on the fabrication and processing can be found in a thesis (Cheng 1993).

\section{Raman and SEM observations}

Raman spectra of CVD diamond films were obtained with an ISA JOBIN-YVON U1000 Raman spectrometer using the $514.4 \mathrm{~nm}$ argon line. A JEOL JSM-35 scanning electron microscope (SEM) was used to observe the surface morphology and the cross-sectional view of the CVD diamond films.

\subsection{Methane concentration}

Figure 2 shows a comparison of the Raman spectra based on the methane concentrations used during film deposition. Raman spectrum of $\mathrm{B} 1\left(0.5 \% \mathrm{CH}_{4}\right)$ shows a sharp peak at $1330 \mathrm{~cm}^{-1}$ with FWHM of $7 \mathrm{~cm}^{-1}$ ( $\mathrm{a}$ in figure 2). This spectrum also shows a very broad band centered around $1550 \mathrm{~cm}^{-1}$. Spectrum $\mathrm{c}$ is the Raman spectrum for the sample $\mathrm{B} 4\left(1.0 \% \mathrm{CH}_{4}\right)$. Again a very sharp peak at $1330 \mathrm{~cm}^{-1}$ is observed 


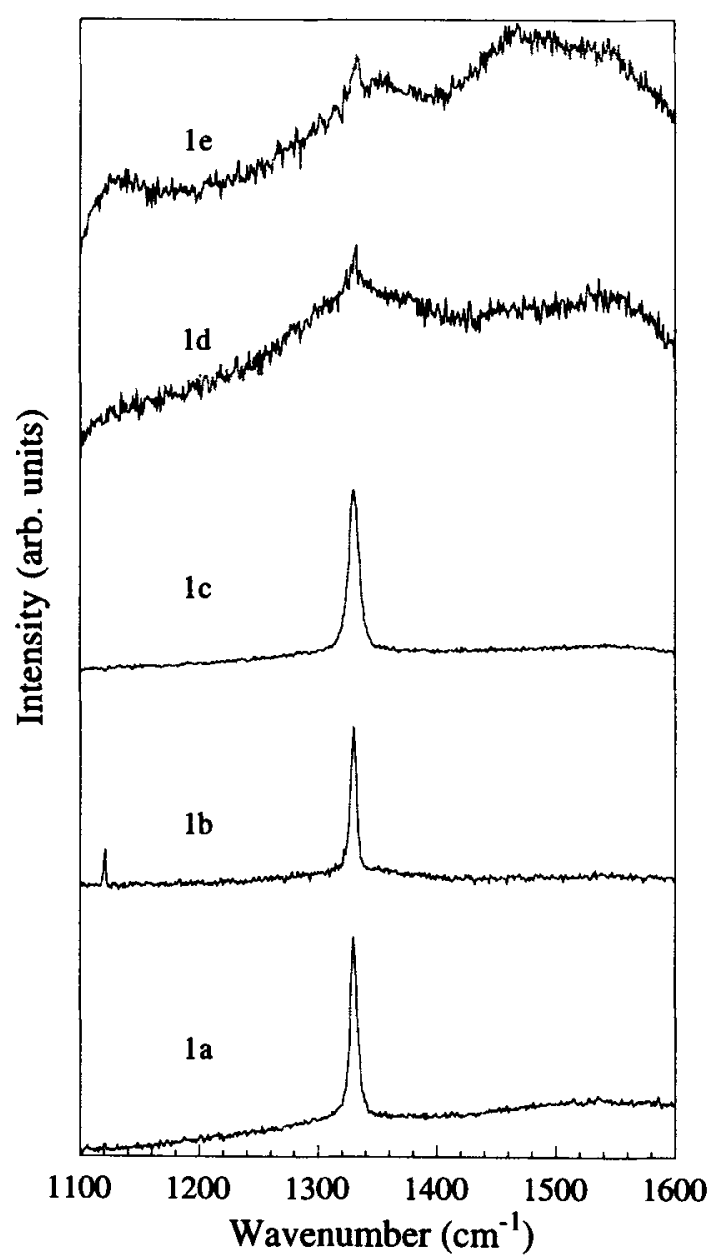

Figure 2. Raman spectra for different methane concentrations: a, $0.5 \% ; \mathrm{b}, 0.75 \% ; \mathrm{c}, 1.0 \%$; d, $1.5 \%$ e, $2.0 \%$.

along with a broad band centered around $1550 \mathrm{~cm}^{-1}$. A very different Raman spectrum is observed for the sample B5 $\left(1.5 \% \mathrm{CH}_{4}\right.$, spectrum d). There is not only a very small diamond peak at $1330 \mathrm{~cm}^{-1}$ but also a well-defined broad band with a peak at $1550 \mathrm{~cm}^{-1}$. Spectrum e is the Raman spectrum for the sample B6 $\left(2.0 \% \mathrm{CH}_{4}\right)$. This spectrum is different from that for the $1.5 \% \mathrm{CH}_{4}$ sample, indicating significant non-diamond phases of carbon. The corresponding SEM pictures for the samples B1, B2, B4 and B5 are shown in figure 3, a-d. As seen in figure 3a, sample B1 $\left(0.5 \% \mathrm{CH}_{4}\right)$ shows a continuous film without regular facets but large grains (average grain size $3.49 \mu \mathrm{m}$ ). In a few other samples with $0.5 \% \mathrm{CH}_{4}$, the films were discontinuous. Increasing the methane concentration to $0.75 \%(B 2$, figure $3 \mathrm{~b})$, we observe a dramatic change in the surface morphology. The sample contains mostly (100) facets and there is a decrease in the grain size (average grain size $1.38 \mu \mathrm{m}$ ). Figure 3c shows the SEM picture of sample $\mathrm{B} 4\left(1.0 \% \mathrm{CH}_{4}\right)$. It is a continuous film showing both (111) and (100) facets; however, (111) facets dominate [76\% (111) facets]. 
A cross-sectional view of this sample (B4) is shown in figure 4a. This figure shows that crystal sizes are large (average grain size $3 \cdot 16 \mu \mathrm{m}$ ) and the crystals did not coalesce to form columnar structures although the growth time was $17 \mathrm{~h}$. The average thickness of this sample is only about $4 \mu \mathrm{m}$. On the other hand, significantly different surface morphology is observed in figure $3 \mathrm{~d}\left(\mathrm{~B} 5,1.5 \% \mathrm{CH}_{4}\right)$. This picture shows cauliflowerlike ball formation. Table 2 gives the summary of the observations of Raman spectra and SEM pictures for samples B1 to B10.

\subsection{System pressure}

As observed in table 1, samples B1 to B6 were fabricated maintaining a pressure of 50 torr, and the remaining four samples (B7 to B10) were fabricated maintaining a pressure of 40 torr. Two important observations are made comparing the results given in table 2: (i) high-quality CVD diamond films (judged by Raman and SEM figures) were obtained at a lower substrate temperature at 40 torr pressure, (ii) even at $1.5 \%$ methane concentration the quality of the films did not degrade at 40 torr pressure.

Table 2. Summary of the observations of Raman spectra and SEM pictures.

\begin{tabular}{|c|c|c|}
\hline $\begin{array}{l}\text { Sample } \\
\text { no. }\end{array}$ & Raman spectra observations & SEM observations \\
\hline B1 & $\begin{array}{l}\text { Diamond peaks at } 1330-1332 \mathrm{~cm}^{-1} \text { with FWHM } \\
\text { of } 6-11 \mathrm{~cm}^{-1} \text { and a small band centered at } \\
1550 \mathrm{~cm}^{-1}\end{array}$ & $\begin{array}{l}\text { Continuous films without regular } \\
\text { facets but large grains }(3.49 \mu \mathrm{m})\end{array}$ \\
\hline B2 & $\begin{array}{l}\text { Diamond peaks at } 1330-1331 \mathrm{~cm}^{-1} \text { with FWHM } \\
6-9 \mathrm{~cm}^{-1} \text { and almost free of non-diamond } \\
\text { carbon phases }\end{array}$ & $\begin{array}{l}\text { Non-uniform growth with small grain } \\
\text { size }(1 \cdot 38 \mu \mathrm{m}),(100) \text { facets dominate }\end{array}$ \\
\hline B3 & $\begin{array}{l}\text { Diamond peaks at } 1329-1331 \mathrm{~cm}^{-1} \text { with FWHM } \\
\text { of } 4.5-14 \mathrm{~cm}^{-1}\end{array}$ & $\begin{array}{l}(100) \text { and }(111) \text { facets with grain size of } \\
2.27 \mu \mathrm{m}\end{array}$ \\
\hline B4 & $\begin{array}{l}\text { Diamond peaks at } 1329-1330 \mathrm{~cm}^{-1} \text { with FWHM } \\
\text { of } 9-16 \mathrm{~cm}^{-1} \text { and small band of non-diamond } \\
\text { carbon phases }\end{array}$ & $76 \%(111)$ facets \\
\hline B5 & $\begin{array}{l}\text { Non-diamond carbon structure with small } \\
\text { diamond peak }\end{array}$ & Cauliflower-like ball shape with voids \\
\hline B6 & $\begin{array}{l}\text { Non-diamond carbon structure with small } \\
\text { diamond peak }\end{array}$ & Cauliflower-like ball shape with voids \\
\hline B7 & $\begin{array}{l}\text { Diamond peaks at } 1330 \mathrm{~cm}^{-1} \text { with FWHM of } \\
8-9 \mathrm{~cm}^{-1}\end{array}$ & $\begin{array}{l}\text { Mixture of }(111) \text { and }(100) \text { facets; small } \\
\text { grain size }(1.40 \mu \mathrm{m})\end{array}$ \\
\hline B8 & $\begin{array}{l}\text { Diamond peaks at } 1329-1331 \mathrm{~cm}^{-1} \text { with FWHM } \\
\text { of } 9-12 \mathrm{~cm}^{-1} \text { and almost free of non-diamond } \\
\text { carbon phases }\end{array}$ & $\begin{array}{l}\text { Continuous film with large grain size } \\
(3.40 \mu \mathrm{m}),(111) \text { facets dominate }\end{array}$ \\
\hline B9 & $\begin{array}{l}\text { Diamond peaks at } 1329-1330 \mathrm{~cm}^{-1} \text { with FWHM } \\
\text { of } 10 \mathrm{~cm}^{-1} \text { and aimost free of non-diamond } \\
\text { carbon phases }\end{array}$ & $\begin{array}{l}\text { (111) facets dominate }(86 \%) \text { grain size } \\
\text { is about } 2.55 \mu \mathrm{m}\end{array}$ \\
\hline B10 & $\begin{array}{l}\text { Diamond peaks at } 1331 \mathrm{~cm}^{-1} \text { and a band centered } \\
\text { at } 1550 \mathrm{~cm}^{-1}\end{array}$ & $\begin{array}{l}\text { Mixture of }(111) \text { and }(100) \text { facets, grain } \\
\text { size is about } 2 \cdot 20 \mu \mathrm{m}\end{array}$ \\
\hline
\end{tabular}



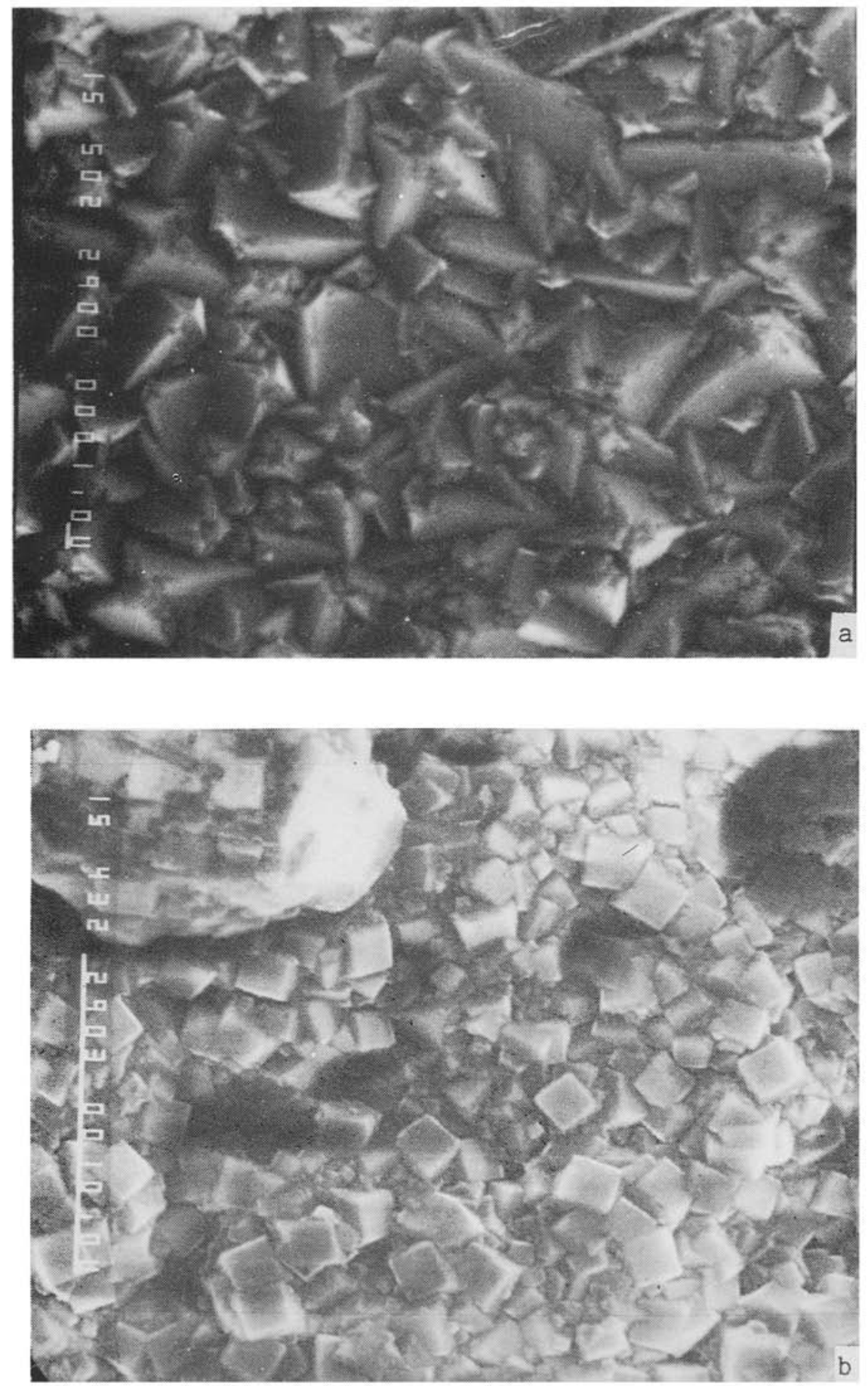

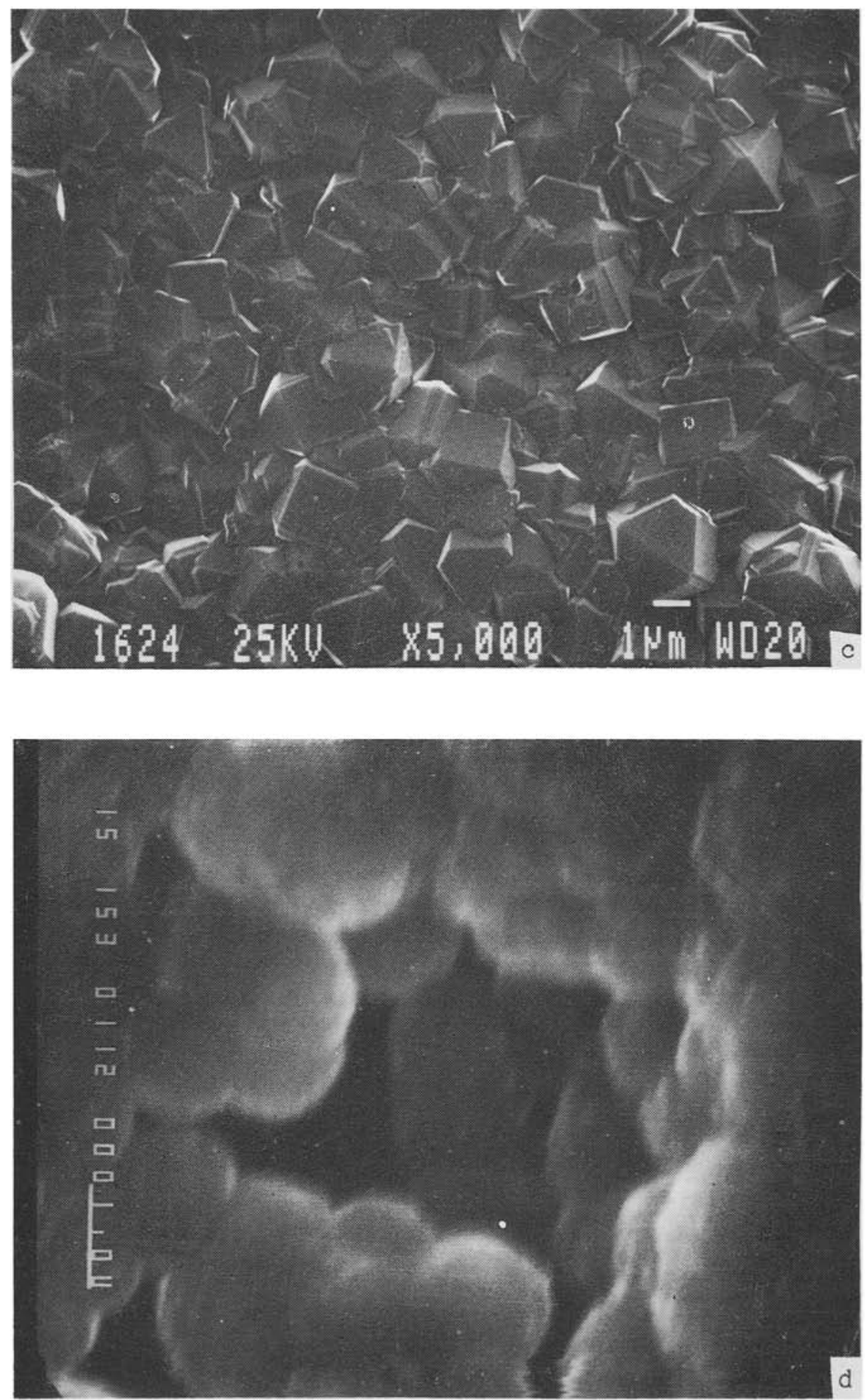

Figure 3. SEM photograph of a. sample B1 $\left(0 \cdot 5_{0}^{\circ} \mathrm{CH}_{4}\right)$, magnification $5000 \times$; b. sample B2 $\left(0.75^{\circ}{ }_{0} \mathrm{CH}_{4}\right)$. magnification $3900 \times$ : c. sample B4 $\left(1.0_{0}^{\circ} \mathrm{CH}_{4}\right)$. magnification $5000 \times$; d. sample $\mathrm{B} 5\left(15^{\circ}{ }_{0} \mathrm{CH}_{4}\right)$, magnification $(\times 5000)$. 

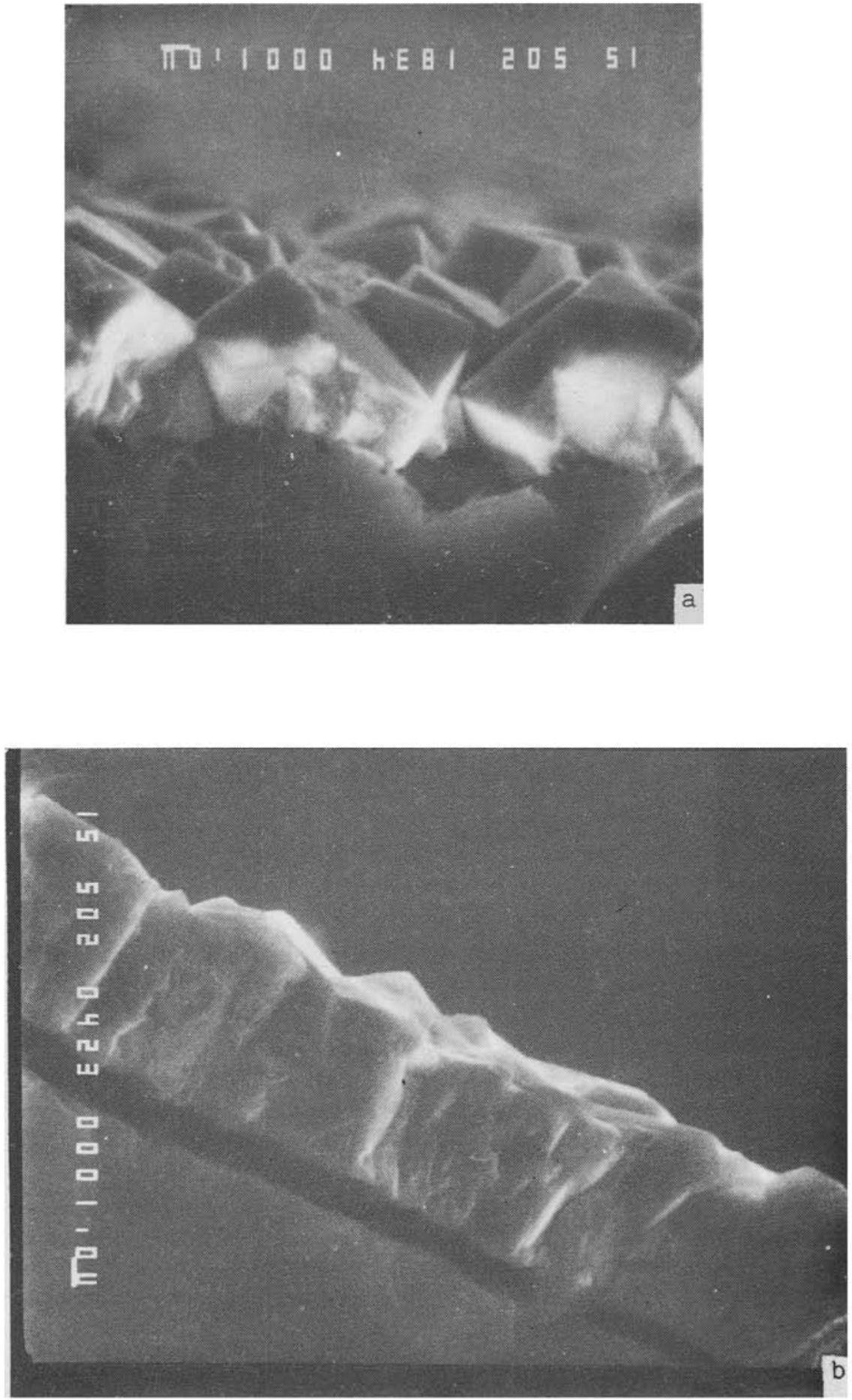

Figure 4. SEM cross-sectional view of a. B4 $\left(1 \cdot 0 \% \mathrm{CH}_{4}\right)$, magnification $5000 \times$; b. B8 $\left(1.0 \% \mathrm{CH}_{4}\right)$, magnification $5000 \times$. 


\subsection{Substrate temperature}

Comparing samples $\mathrm{B} 8$ and $\mathrm{B} 9\left(875^{\circ} \mathrm{C}\right.$ vs $\left.810^{\circ} \mathrm{C}\right)$ it is observed that the average grain size of the diamond crystals increases from $2.55 \mu \mathrm{m}$ with increase in substrate temperature. The quality of the films grown at $810^{\circ} \mathrm{C}$ substrate temperature appears to be superior (see figure $4 \mathrm{~b}$, a cross-sectional SEM picture of sample B8), showing columnar growth and compact structure.

\section{Sheet resistivity}

Electrical characterization of polycrystalline CVD diamond films is necessary to determine the feasibility of these films for high-temperature electronic applications.
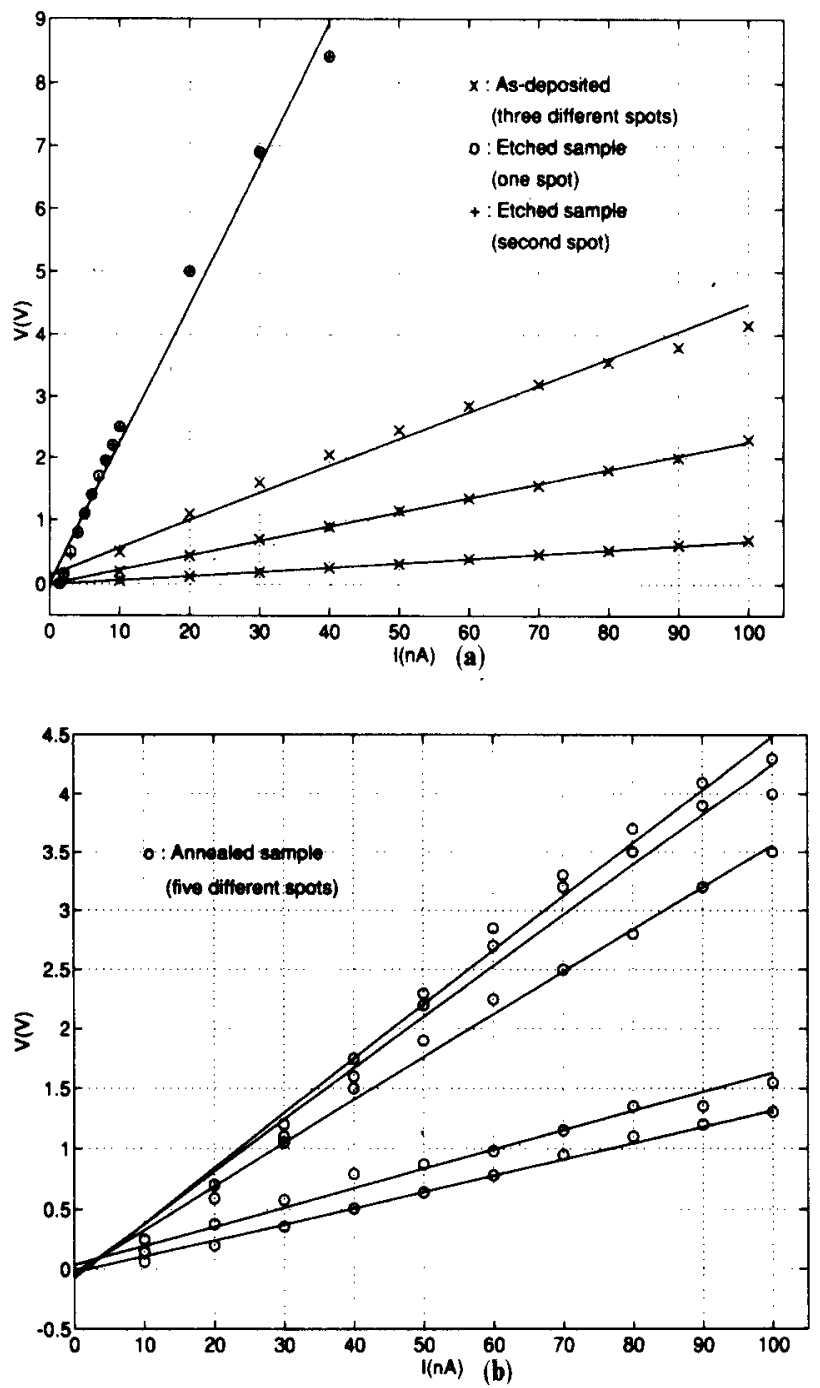

Figure 5. Current-voltage characteristics of a. a typical as-deposited sample measured by four-point probe techniques; also shown is the characteristic after etching chemically; $\mathbf{b}$. sample after annealing in vacuum at $850^{\circ} \mathrm{C}$ for $30 \mathrm{~min}$. 
A common method for measuring the sheet resistance of thin films is the four-point probe method. Details of the measurement procedure are described elsewhere (Shrotriya 1993). Figure 5a shows the current-voltage characteristics of a typical as-deposited diamond thin-film sample measured by four-point probe techniques. The growth parameters for this sample were as follows: methane to hydrogen ratio $1 \%$, system pressure 40 torr, substrate temperature $850^{\circ} \mathrm{C}$, filament temperature $\geqslant 1850^{\circ} \mathrm{C}$, high-resistivity $(>100 \mathrm{k} \Omega-\mathrm{cm})<100>$ oriented silicon substrates.

The three different curves for the as-deposited sample represent measurements on three different spots on the same sample. Assuming a thickness of $10 \mu \mathrm{m}$ for this sample the average resistivity for the as-deposited sample is $8.68 \pm 6.56 \times 10^{4} \Omega$-cm. Such a large variation in the resistivity is due to either graphitic regions in between diamond crystals or hydrogen absorbed on the surface. Also shown in this figure is the current-voltage characteristic of a chemically etched sample. The sample was etched in a saturated solution of $\mathrm{CrO}_{3}$ and $\mathrm{H}_{2} \mathrm{SO}_{4}$ for $1 \mathrm{~h}$. As seen in this curve, the data from two different spots overlap. The sheet resistivity increased to $7.90 \times 10^{5}$ $\Omega-\mathrm{cm}$. Such dramatic changes in the sheet resistivity as well as surface texture and composition of the film after chemical etching are described in detail in another paper (Kulkarni et al 1994). Figure $5 \mathrm{~b}$ shows the current-voltage characteristics of the same sample after it was annealed in vacuum at $850^{\circ} \mathrm{C}$ for $30 \mathrm{~min}$. Again the five curves correspond to five different spois on the same sample. The average sheet resistivity of this sample increased to $1.10 \pm 0.57 \times 10^{5} \Omega$-cm after annealing. In general, we have observed sheet resistivities in the range of $10^{2}$ to $10^{5} \Omega$-cm for as-deposited undoped diamond films.

\section{Discussion}

\subsection{Nucleation}

The nucleation and growth of CVD diamond films on silicon substrates is strongly dependent on substrate preparation (Williams and Glass 1989). We used diamond pastes with different particle sizes $(9 \mu \mathrm{m}$ and $1 \mu \mathrm{m})$ to scratch the silicon substrates. The samples B1 to B5 were scratched with $9 \mu \mathrm{m}$ diamond paste and had rougher surfaces. From figure $4 \mathrm{a}$ (cross-sectional SEM picture), one can estimate a nucleation density of about $1.3 \times 10^{7} \mathrm{~cm}^{-2}$ ( 8 crystals within $22 \mu \mathrm{m}$ length). The nucleation density is estimated to go up by seven orders of magnitude $\left(10^{4}\right.$ to $\left.10^{11} \mathrm{~cm}^{-2}\right)$ from unscratched silicon substrates to heavily scratched silicon substrates (Kweon et al 1991). It is known that CVD diamond growth on silicon causes the development of a $\beta$-SiC (cubic zinc-blended crystal structure) interlayer between silicon and diamond in the initial stages of growth (Belton et al 1989; Meilunas et al 1989). A clear understanding of the nucleation of diamond on silicon substrates is crucial for the development of high-quality epitaxial diamond thin films on silicon substrates.

\subsection{Growth}

Depending on substrate preparation, growth method and growth conditions largegrained $(>1 \mu \mathrm{m})$ polycrystalline to submicrocrystalline $(<0.1 \mu \mathrm{m})$ CVD diamond thin films are grown. Epitaxial growth of single-crystalline diamond on non-diamond 
substrates such as silicon has remained a challenge that has to be addressed if high-temperature diamond electronic devices are to be fabricated and used in everyday life. The dependence of the structural properties of the film on three important growth parameters, viz. methane to hydrogen ratio, substrate temperature and system pressure, are described in detail, comparing our experimental results with the results of other investigators.

5.2a Methane concentration: With increasing methane concentration from 0.5 to $2.0 \%$ dramatic changes are observed in both Raman spectra (figure 2 ) and surface morphology (figure 3). A few other investigators have also observed the broadening of the diamond peak (larger FWHM) and increasing intensities of peaks due to nondiamond carbon phases with an increase in the methane concentration in HFCVD diamond films (Mercier et al 1991; Kweon et al 1991). With increasing methane concentration (up to $1.0 \%$ or $1.5 \%$ ) the growth rate increases to yield continuous films with regular facets. However, very high methane concentrations $(>1.5 \%)$ increase the formation of graphitic phase as a direct consequence of a decrease in atomic hydrogen flux. Both Raman and SEM data substantiate this observation. On the contrary, for methane concentrations below $0.5 \%$, the etching rate of diamond and graphite due to atomic hydrogen exceeds the growth rate resulting in discontinuous films. The decrease of grain size with increasing methane concentration (from 0.5 to $0.75 \%$ ) is attributed to carbon supersaturation in the gas phase and nucleation enhancement. Zhu et al (1990) observed the surface morphology of CVD diamond films to indicate that triangular (111) faces changed to square (100) faces when methane concentration was increased from 0.5 to $2.0 \%$. These authors observed ball-shape formation at higher substrate temperatures and higher $(5 \%)$ methane concentration. Our results agree with those of Zhu et al (1990) at high methane concentrations, but there is a disagreement about the types of facets, (100) vs (111), at lower methane concentrations. Similar to our results, Spitsyn et al (1981) observed (111) facets for high methane concentrations and low substrate temperatures and (100) facets for low methane concentrations and high substrate temperatures. The formation of facets is a function of carbon supersaturation, nucleation rate, carbon atom mobility on the surface, and surface restructuring processes such as fusion and absorption among secondary crystallites (Kobashi et al 1988).

5.2b Substrate temperature: Substrate temperature controls the mobility of the carbon atoms on the growing surface and hence affects nucleation, surface restructuring and quality thin-film growth. It is well known that there is a working temperature range $\left(800-1000^{\circ} \mathrm{C}\right)$ for growing large-grain-size $(1-5 \mu \mathrm{m})$ diamond thin films by CVD methods (Kondoh et al 1992). Very high substrate temperatures $\left(>1300^{\circ} \mathrm{C}\right)$ result in the formation of graphitic carbon (Spitsyn et al 1981) and grain sizes of diamond thin films decrease with decreasing substrate temperatures $(200 \mathrm{~nm}$ at $650^{\circ} \mathrm{C}, 10-20 \mathrm{~nm}$ at $500^{\circ} \mathrm{C}$ ). We observed an increase in average grain size from $2.55 \mu \mathrm{m}$ to $3.40 \mu \mathrm{m}$ with increasing substrate temperature from $810^{\circ} \mathrm{C}$ to $875^{\circ} \mathrm{C}$ under identical growth conditions.

5.2c System pressure: The system pressure during growth affects mainly the flux of atomic hydrogen to the growing surface and the recombination of atomic hydrogen 
to form molecular hydrogen (Mercier et al 1991). At high pressures ( $>50$ torr) the hydrogen flux decreases resulting in graphite formation and at low pressures $(<50$ torr) the hydrogen flux increases to result in efficient etching of graphite form of carbon. However, increasing hydrogen flux also enhances hydrogen incorporation in diamond films. Large-grain-size $(10 \mu \mathrm{m})$ diamond crystals are typically grown at pressures from 20 to 100 torr depending upon other growth parameters and the system used. Our limited experimental results at two different pressures (50 torr and 40 torr) showed a remarkable improvement in the quality of the films at 40 torr compared to those films grown at 50 torr.

Some other growth parameters such as filament temperature, gas flow rates, biasing of the substrate, filament to substrate distance and types of gases used also affect the quality of the diamond thin films to a limited extent.

5.2d Sheet resistivity: The sheet resistivities of the as-deposited undoped diamond films are reported to be in the range of $10^{2}-10^{6} \Omega-\mathrm{cm}$ (Landstrass and Ravi 1989a; Ramesham et al 1991). The low sheet resistivity of undoped CVD diamond films is attributed either to the hydrogen passivation of defect states (Landstrass and Ravi 1989b; Albin and Watkins 1990) or to the presence of disordered graphitic regions between the grains (Shiomi et al 1990; Muto et al 1991; Kulkarni et al 1994). This low resistivity of as-deposited films can be enhanced significantly either by annealing beyond $800^{\circ} \mathrm{C}$ to remove hydrogen from the surface layers (Landstrass and Ravi 1989a; Albin and Watkins 1990) or by chemically etching the films in a saturated solution of $\mathrm{CrO}_{3}$ and $\mathrm{H}_{2} \mathrm{SO}_{4}$ (Muto et al 1991; Kulkarni et al 1994). The sheet resistivities in the range of $10^{2}-10^{5} \Omega$-cm observed for the undoped diamond films in our experimental work agree well with the reported values. An order-of-magnitude increase in the resistivity was observed in the chemically etched sample. In several chemically etched samples the very high resistivity could not be measured because of the limited scope of the measurement techniques.

\section{Conclusions}

Chemical vapour deposition of diamond thin films for a variety of applications has advanced rapidly in the last decade. However, large-scale commercialization of this vapour-phase-growth technology is yet to be realized. The major hindrance to the development of this technology has been the inability to grow high-quality singlecrystalline diamond films on economically inexpensive non-diamond substrates. This review paper has attempted to summarize recent results in chemical vapour deposition of diamond thin films on silicon substrates. In particular, the dependence of the characteristics of the films as determined by Raman spectroscopy and scanning electron microscopy on growth parameters such as methane to hydrogen ratio, substrate temperature and system pressure has been discussed in detail. Dramatic changes were seen in the Raman spectra (crystalline diamond to graphitic and amorphous carbon) as well as surface morphology (faceted structures to cauliflowertype ball shapes) with changes in methane to hydrogen ratio of $0.5 \%$ to $2.0 \%$. The sheet resistivities of the films were in the range $10^{2}-10^{4} \Omega-\mathrm{cm}$ for the as-deposited samples. The effect of chemical etching and annealing on the sheet resistivity have been discussed. The correlation of the electrical properties of these films with the structural properties which in turn depend on the growth parameters will lead to 
better understanding of the control of the electrical characteristics of these films for semiconductor device applications.

\section{Acknowledgements}

The author acknowledges partial financial support from the State of Michigan Research Excellence Funds. This review work has been the combined effort of several graduate students and faculty at Michigan Technological University. The students, P Cheng, A Shrotriya, R Bashyam and K Tey, are responsible for the growth and characterization of the diamond thin films. Useful discussions and support from Professors H Rodrigo, D J Keeble and S Hackney are appreciated. Finally, I am grateful to Alice Slusarzyk for typing this manuscript.

\section{References}

Albin S and Watkins L 1990 Appl. Phys. Lett. 561454

Angus J C and Hayman C C 1988 Science 241913

Belton D N, Harris S J, Schweis S J, Weimer A M and Perry T A 1989 Appl. Phys. Lett. 54415

Cheng P 1993 Growth and characterization of diamond thin films deposited on silicon substrates MS thesis, Michigan Technological University, Houghton, USA

Davis R F 1993 Diamond films and coatings (Park Ridge, NJ: Noyes Publications)

Kobashi K, Nishimura K, Kawate Y and Horinchi T 1988 Phys. Rev. B38 4067

Kobashi K, Nishimura M K, Kumagai K and Kawate Y 1989 Proc. 1st Electro. Chem. Soc. Intl. Symp. on Diamond and Diamond-Like Coatings 89296

Kondoh E, Ohta T, Mitomo T and Ohtusuka K 1992 J. Appl. Phys. 72705

Kulkarni A K, Shrotriya A, Cheng P, Rodrigo H, Bashyam R and Keeble D J 1994 Thin Solid Films 253141

Kweon D, Lee J and Kim D 1991 J. Appl. Phys. 698329

Landstrass M I and Ravi K V 1989a Appl. Phys. Lett. 55975

Landstrass M I and Ravi K V 1989b Appl. Phys. Lett. 551391

Matsumoto S, Sato Y, Tsutsumi M and Setaka 1982 J. Mater. Sci. 173106

Meilunas R, Wong M S, Sheng K C and Chang R P H 1989 Appl. Phys. Lett. 542204

Mercier J, Bonnot A M, Caignol E and Gheeraert 1991 in Diamond and diamond-like films and coatings (eds) R E Clausing, L L Horton, J C Angus and P Koidl (New York: Plenum Press) p. 533

Muto Y T, Sugino J, Shirafuji J and Kobashi K 1991 Appl. Phys. Lett. 59843

Ramesham R, Roppel T and Ellis C 1991 J. Electrochem. Soc. 1362981

Shiomi H. Tanake K, Nishibayashi Y and Fujimori N 1990 Jpn. J. Appl. Phys. 2934

Shrotriya A 1993 Electrical and structural characterization of diamond thin films grown by chemical vapor desposition MS thesis, Michigan Technological University, Houghton, USA

Spitsyn B V, Bouilov L L and Deryagin 1981 J. Cryst. Growth 52219

Stoner B R, Glass J T, Bergman L, Nemanich R J, Zoltral L D and Vandersande J W 1992 J. Electronic Mater. 21629

Williams B E and Glass J T 1989 J. Mater. Res. 4373

Yarbrough W A and Messier R 1990 Science 247688

Zhu W, Badzian A R and Messier R 1990 Proc. of SPIE on Diamond Optics III 1325187

Zhu W, Stoner B R, Williams B E and Glass J T 1991 Proc. IEEE 79621 